\title{
Artigo \\ Fogão solar do tipo painel com materiais de baixo custo: Uma alternativa para cocção de alimentos
}

\author{
Carlos Alberto Faustino Neto ${ }^{[1]}$ e Fabiana Karla de Oliveira Martins Varella Guerra ${ }^{[2]}$ \\ [1] Universidade Federal Rural do Semi-Árido do Rio Grande do Norte; cafn1997@gmail.com \\ ${ }^{[2]}$ Universidade Federal Rural do Semi-Árido do Rio Grande do Norte; fkv@ufersa.edu.br \\ Recebido: 10/06/2020; \\ Aceito: $27 / 07 / 2020$ \\ Publicado: 11/09/2020.
}

Resumo: O uso do fogão solar tem tido elevada importância no cenário mundial, sendo normalmente considerado como uma tecnologia de fácil construção e manutenção, quando se utiliza de materiais de baixo custo para sua confecção. Sendo assim, devido à crescente preocupação ambiental, os fogões solares vem sendo considerados uma excelente alternativa para o aproveitamento da radiação solar, energia gratuita, sendo viável principalmente para as famílias de baixa renda ou que vivem em comunidades rurais, distantes dos grandes centros. Por todo exposto, o presente artigo tem como objetivo realizar a construção de um fogão solar do tipo painel modelo cookit e verificar a sua viabilidade na cidade de Mossoró no Rio Grande do Norte. O fogão solar foi confeccionado utilizando materiais de baixo custo e a análise do seu desempenho foi realizada por intermédio de um estudo comparativo do fogão desenvolvido no presente artigo com a literatura existente. De modo que, foi possível observar que apesar da cidade se encontrar em períodos nublados e chuvosos na fase dos ensaios, o fogão solar ainda assim realizou o processo de cozimento dos alimentos, demonstrando pleno funcionamento.

Palavras-chave: energia solar; fogão solar; cookit

Abstract: The use of solar cooker has had a high importance around the world scenario, being normally considered with a technology of easy construction and maintenance, when it is used low cost materials for its confection. For that reason, due to the growing environmental concern, the solar cookers have been considered an excellent alternative for the use of solar radiation, free energy, being viable mainly for low-income families or people who live in rural communities, far from large centers. That being said, this article has the purpose to build a solar cooker whose type is panel cookit model and examine its viability in the city of Mossoró in Rio Grande do Norte. The solar stove was built of low cost materials and the analysis of its performance was carried out through a comparative study of the solar cooker developed in this article with the existing literature. So that, it was possible to observe that, despite the city being in cloudy and rainy periods during the testing phase, the solar cooker still perfomed the cooking process of the food, demonstrating ample operation.

Key-words: solar energy; solar cooker; cookit

\section{INTRODUÇÃO}

$\mathrm{A}$ s fontes renováveis de energia são aquelas consideradas inesgotáveis para os padrões humanos de utilização, e têm como característica se renovarem [1]. Alguns exemplos de fontes desse tipo são as de energia solar, hidrelétrica, eólica, dos oceanos, geotérmica e de biomassa.

Ademais, existem outros fatores classificatórios para as fontes de energia, alguns deles são os casos das fontes convencionais que historicamente foram utilizadas como solução para o suprimento energético; as fontes alternativas que são fontes de energia que estão surgindo como alternativa às fontes convencionais; [2] e as fontes sustentáveis que são as que contribuem com o desenvolvimento sustentável da sociedade. Tal 
desenvolvimento se trata, em essência, de um processo de transformação no qual a exploração dos recursos, a direção dos investimentos, a orientação do desenvolvimento tecnológico e a mudança institucional se harmonizam e reforçam o potencial presente e futuro, a fim de atender às necessidades e aspirações humanas [3].

Diante disso, tem-se a energia solar, proveniente da luz e calor do Sol, renovável, alternativa e sustentável, além de ser utilizada por intermédio de diversas tecnologias, a saber, o uso das células fotovoltaicas que são dispositivos que atuam utilizando o princípio do efeito fotoelétrico ou fotovoltaico [4], dos sistemas de aquecimento que utilizam o calor captado por coletores solares instalados nos telhados de prédios ou residências para aquecer água [1], dos secadores solares que são dispositivos que utilizam da energia solar para secagem de grãos, frutas e outros produtos alimentícios [5], entre outros mecanismos tecnológicos.

Adicionando-se à questão, há outra aplicação da energia solar que é a sua utilização em fogões e fornos, que trata do tema do presente artigo. Desse modo, fogões solares são utilizados para a cocção de alimentos usando apenas a fonte de energia solar, e sua fabricação pode ser feita com material reaproveitado e de baixo custo [6]. Além disso, este tipo de aplicação é de extrema importância para o desenvolvimento sustentável da sociedade, pois contribui para diminuição do consumo da lenha e do gás liquefeito de petróleo com a substituição destes pela energia solar, que se trata de uma fonte energética abundante e limpa, causando-se assim ínfimos impactos ambientais. Uma outra vantagem consiste na ausência de chamas, fumaça, perigo de explosão, incêndios, entre outros, o que se encaixa perfeitamente para situação de alguns países pobres que possuem problemas de saúde associados à intoxicação por fumaça, principalmente de mulheres e crianças [7].

Em relação aos tipos de fogões solares, estes são classificados no tipo painel, tipo caixa, tipo parabólico, tipo elíptico, entre outros [8]. Dessa forma, o presente artigo tem por objetivo realizar a construção de um fogão solar do tipo painel, de modo que, após realizar testes com alguns alimentos, será verificada a sua viabilidade na cidade de Mossoró/RN. Tendo isso em vista, para verificação da viabilidade do fogão, foram cozidos alimentos no fogão solar construído e os resultados obtidos foram analisados e comparados com o que foi desenvolvido por [9].

\section{FOGÃO SOLAR}

Como já mencionado, fogões solares são equipamentos utilizados para o cozimento de alimentos usando apenas energia solar e sua fabricação pode ser feita com material simples e de baixo custo [7], além de permitir a execução de outros processos tais como esterilização e pasteurização [10]. Além disso, para o funcionamento de tais equipamentos, algumas condições [8] devem ser atendidas, tais como, a necessidade de um local ao ar livre, ensolarado por várias horas e protegido do vento forte, onde os alimentos estarão seguros, de modo que o seu funcionamento não ocorre pela noite e o seu rendimento é afetado em dias nublados; o uso de panelas de metal escuras, rasas e finas com tampas escuras e bem ajustadas para reter o calor e a umidade; a utilização de sacos plásticos transparentes ou de coberturas de vidro na panela para retenção do calor e melhoramento do rendimento da cocção por intermédio do efeito estufa; e a implementação de uma ou mais superfícies brilhantes no fogão para auxiliar a reflexão de luz solar extra na panela, o que intensifica o calor. Em relação à classificação, existem alguns modelos e variações de fogões solares no mundo, que são continuamente aperfeiçoados por pesquisadores e fabricantes, o que dificulta uma classificação exata. Todavia, os três tipos de fogões solares mais comuns e estudados são os fogões do tipo caixa, tipo painel e tipo parabólico [8,10].

\subsection{Fogões Solares do Tipo Caixa}

São fogões construídos com caixas, as quais podem ser de papelão, madeira ou plástico, de modo que a face superior é constituída por uma tampa de vidro para que ocorra o efeito estufa, e possui abas ou refletores laterais que concentram a energia térmica solar dentro da caixa, além da utilização de isopor para o isolamento térmico [7,11]. Incrementando-se à questão, tais fogões costumam cozinhar alimentos com temperaturas em torno de $90{ }^{\circ} \mathrm{C}$ a $200{ }^{\circ} \mathrm{C}$ [8], e possuem tempo de cocção lento quando comparado com outros modelos [12]. Por todo o mundo, estes são os mais difundidos, de modo que somente na Índia existem centenas de milhares de fogões desta configuração [8]. A Figura 1 mostra um fogão solar do tipo caixa. 


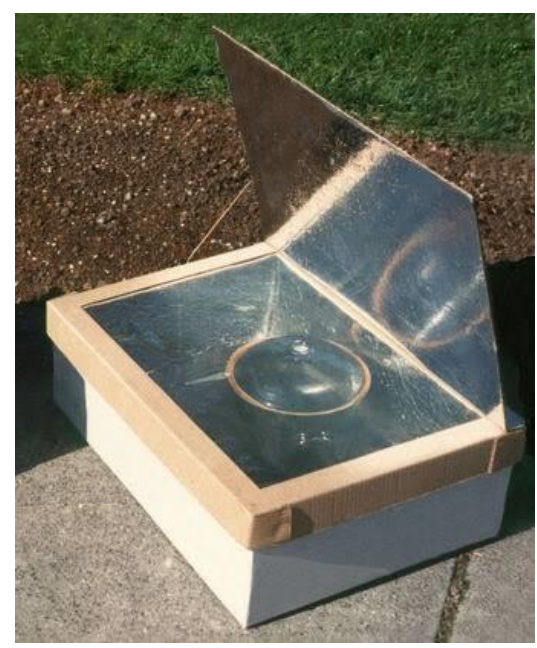

FIGURA 1. Fogão solar do tipo caixa [13].

\subsection{Fogões Solares do Tipo Painel}

São fogões construídos por painéis acartonados ou papelão que são revestidos com uma superfície reflexiva a qual pode ser de papel alumínio, filme de poliéster metalizado, folha de saco de embalagem metalizada para presente, entre outros [7]. Dessa forma, os painéis são inclinados de modo a concentrar o foco onde será colocada a panela, a qual deve ser coberta com sacos plásticos para fornos ou recipiente de vidro transparente, o que proporciona o efeito estufa para reter o calor e aperfeiçoar significativamente o rendimento da cocção [7]. Ademais, tal modelo de fogão apresenta baixo rendimento, o que proporciona um elevado tempo de cozimento, e alcança temperaturas de cozimento aproximadamente iguais a $150{ }^{\circ} \mathrm{C}[7,8]$. Contudo, a cocção lenta dos alimentos preserva melhor os nutrientes, o que se resulta em comidas mais saudáveis [7]. Diante disso, existem diversos modelos de fogões solares do tipo painel tais como o cookit, fun panel, sunny, funil, windshield shade, educooker, entre outros, sendo o cookit, considerado o modelo mais popular desta categoria [7,10]. A Figura 2 mostra um fogão solar do tipo painel.

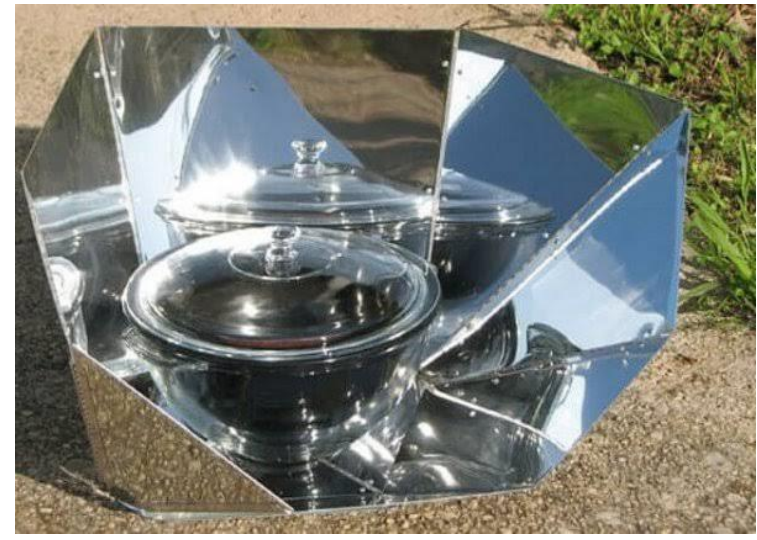

FIGURA 2. Fogão solar do tipo painel [14].

\subsection{Fogões Solares do Tipo Parabólico}

São fogões constituídos por uma (vide Figura 3) ou mais parábolas com foco convergente preciso, a qual pode ser de diversos materiais tais como aço, fibra de vidro, plástico moldado, papelão, alumínio polido em estrutura de apoio, entre outros [7]. De modo que tais estruturas parabólicas concentram e direcionam a radiação solar para um ponto focal onde se localiza o recipiente com a comida [15]. Além disso, este tipo de fogão solar exige uma reorientação focal mais frequente, possivelmente a cada 15 minutos [7]. Todavia, tal modelo apresenta o melhor rendimento em relação aos outros tipos de fogões supracitados, cozinhando alimentos com temperaturas geralmente acima de $200{ }^{\circ} \mathrm{C}$, o que se resulta em um menor custo de tempo na cocção [8]. 


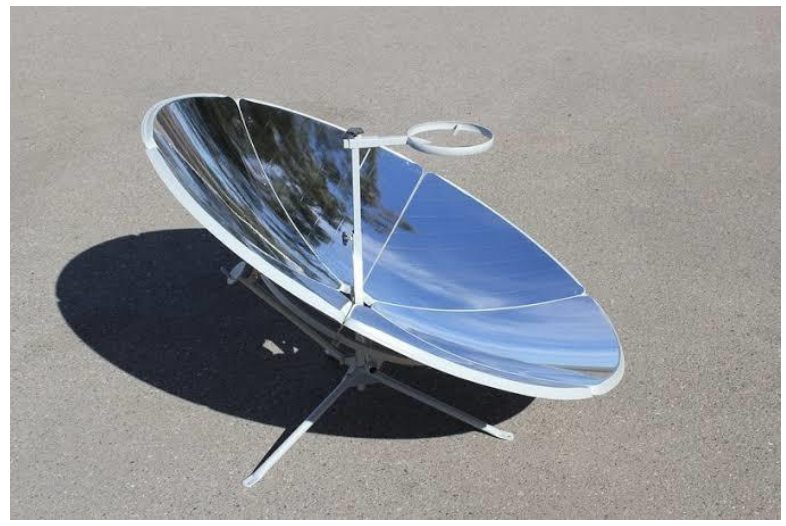

FIGURA 3. Fogão solar do tipo parabólico [16].

O tipo de fogão solar mostrado na Figura 3, além de cozinhar, permite fritar e assar comidas com rendimento igual ou superior a energia térmica da chama de fogão a gás convencional [7]. Contudo, é necessário ressaltar que durante o período de funcionamento, os fogões parabólicos devem ser monitorados periodicamente para evitar queimar os alimentos no fundo da panela [8]. Ademais, recomenda-se o uso de proteção aos olhos e ao corpo evitando danos oftalmológicos ou queimaduras na pele, entre outros danos à saúde física.

\section{MATERIAIS E MÉTODOS}

De acordo com a pesquisa realizada, a maioria dos trabalhos científicos abordam a cocção solar utilizando de forma predominante os fogões do tipo caixa ou parabólico como é o caso dos trabalhos realizados por [17] e [12] por exemplo. No artigo desenvolvido por [10], é abordada a análise de performance de fogões solares no que diz respeito a teoria, modelos analíticos e numéricos, modelagens, simulações e trabalhos experimentais aplicados majoritariamente para fogões do tipo caixa. Um outro exemplo é o caso do artigo desenvolvido por [18], que aborda fogões solares do tipo painel, mas não com o objetivo de análise da performance, mas sim com o foco em analisar como está se desenvolvendo um projeto para introdução de fogões solares em Burkina Faso.

Diante deste cenário, foram encontradas dificuldades para o desenvolvimento de uma metodologia que possibilitasse a verificação da viabilidade dos fogões solares do tipo painel na cidade de Mossoró. Ao longo da realização da pesquisa, foram identificados os trabalhos desenvolvidos por [9] e [11] que abordam os fogões solares do tipo painel em relação à sua performance. Tais trabalhos tratam sobre a análise do desempenho do fogão solar do tipo painel de acordo com o tempo necessário para cocção de alguns alimentos, utilizando os dados da temperatura e a irradiação solar, entre outros fatores. Desse modo, com o intuito de verificar a viabilidade de fornos solares do tipo painel na cidade de Mossoró, foram cozidos alimentos no fogão solar confeccionado e os resultados obtidos foram analisados e comparados com o que foi desenvolvido por [9].

Além disso, na presente seção será realizada uma descrição do local onde foi desenvolvido o projeto, do processo de construção do fogão solar e do procedimento experimental.

\subsection{Caracterização do Local}

O protótipo foi desenvolvido no município de Mossoró, localizado na região Nordeste, mais especificamente no estado do Rio Grande do Norte. Tal município possui clima semiárido com temperatura média anual máxima de $36,0{ }^{\circ} \mathrm{C}$ e períodos chuvosos entre os meses de fevereiro e abril [19]. Além disso, Mossoró possui uma irradiação solar bastante intensa, com valor global médio diário de cerca de $5.600 \mathrm{Wh} / \mathrm{m}^{2}$, o que favorece a utilização da energia solar [20].

\subsection{Construção do Fogão Solar}

Como já mencionado, o fogão solar construído configura-se como do tipo painel e mais especificamente como do modelo cookit. Dessa forma, foram utilizadas as instruções de montagem do protótipo desenvolvido por [21]. A Figura 4 ilustra o modelo construtivo apresentado por [21]. 


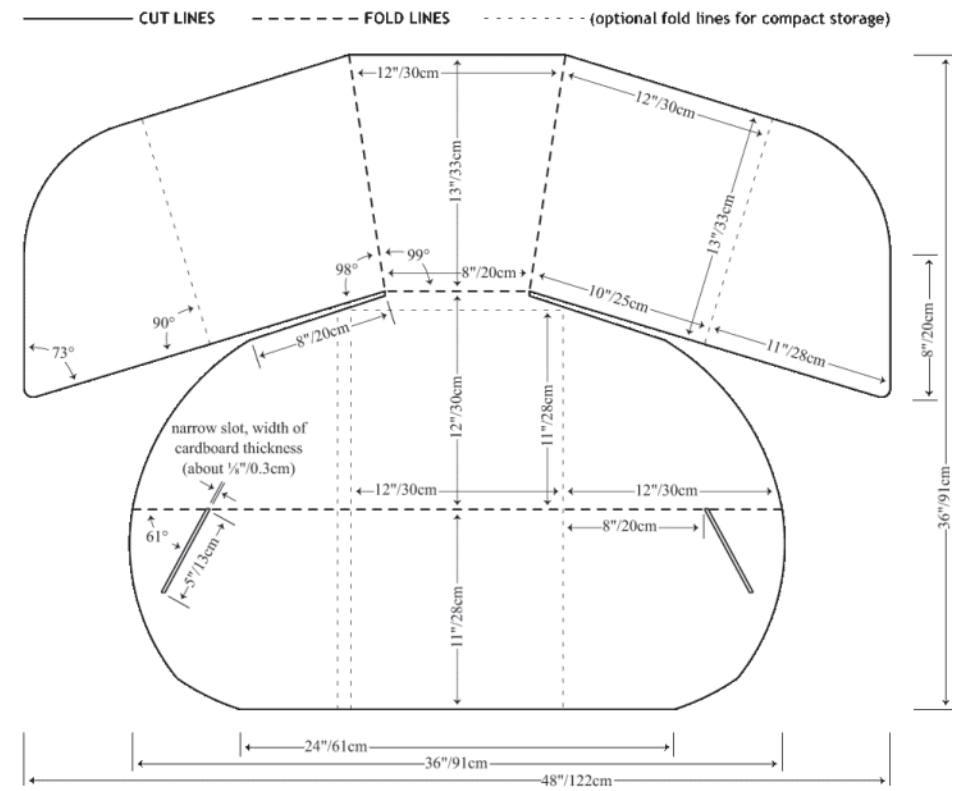

FIGURA 4. Modelo construtivo [21].

Além disso, a Tabela 1 apresenta os materiais utilizados na construção do fogão solar proposto e seus respectivos custos.

TABELA 1. Materiais e seus respectivos custos [22].

\begin{tabular}{cc}
\hline Material & Custo $(R \$)$ \\
\hline Papelão $(1,00 \mathrm{~m} \mathrm{x} \mathrm{1,20} \mathrm{m)}$ & $*$ \\
Trena de $3 \mathrm{~m}$ & $*$ \\
Régua de $50 \mathrm{~cm}$ & $*$ \\
Esquadro $60^{\circ}$ & $*$ \\
Caneta marca texto de cor verde & 4,60 \\
Fita aluminizada de cor prata $(32,50 \mathrm{~cm} \times 50 \mathrm{~m})$ & $*$ \\
Facas de churrasco & 46,00 \\
Panela metálica preta & 30,00 \\
\hline Tuas coberturas de vidro transparente & 80,60 \\
\hline
\end{tabular}

${ }^{*}$ Representa o material adquirido de forma gratuita.

Desse modo, para dar início a confecção do protótipo, foram realizadas as medidas do papelão adquirido, de modo que este apresentou uma mensuração de $1,00 \mathrm{~m}$ x 1,20 m, sendo diferente do modelo construtivo proposto por [21] que é de $0,91 \mathrm{~m}$ x 1,22 m, o que se resultou em adaptações para serem realizadas nas dimensões do fogão. Posteriormente, com o auxílio de uma régua de $50 \mathrm{~cm}$, do esquadro de $60^{\circ}$ e da caneta marca texto de cor verde, foram realizadas as marcações de recorte e dobramento no papelão representando o formato do fogão. A Figura 5 mostra o papelão com as marcações mencionadas. 


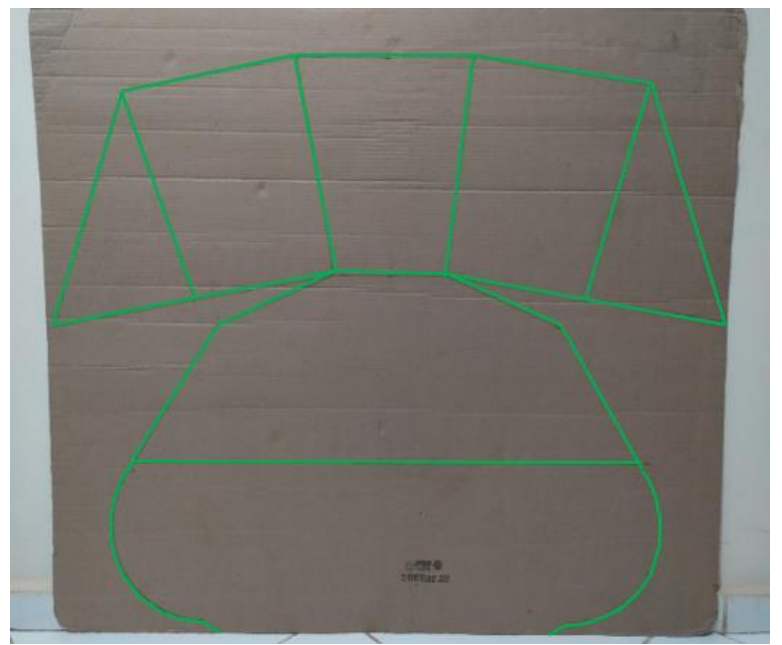

FIGURA 5. Papelão com as marcações [22].

Dando continuidade a confecção do protótipo, a etapa seguinte foi realizar o recorte da área demarcada, que foi revestida com a fita aluminizada de cor prata $(32,50 \mathrm{~cm}$ x $50 \mathrm{~m})$ e dobrada de acordo com as marcações. Com todas as etapas concluídas, finalizou-se a construção do fogão solar do tipo painel modelo cookit (vide Figura 6), que funciona em conjunto com a panela metálica preta dentro das duas coberturas de vidro transparentes.

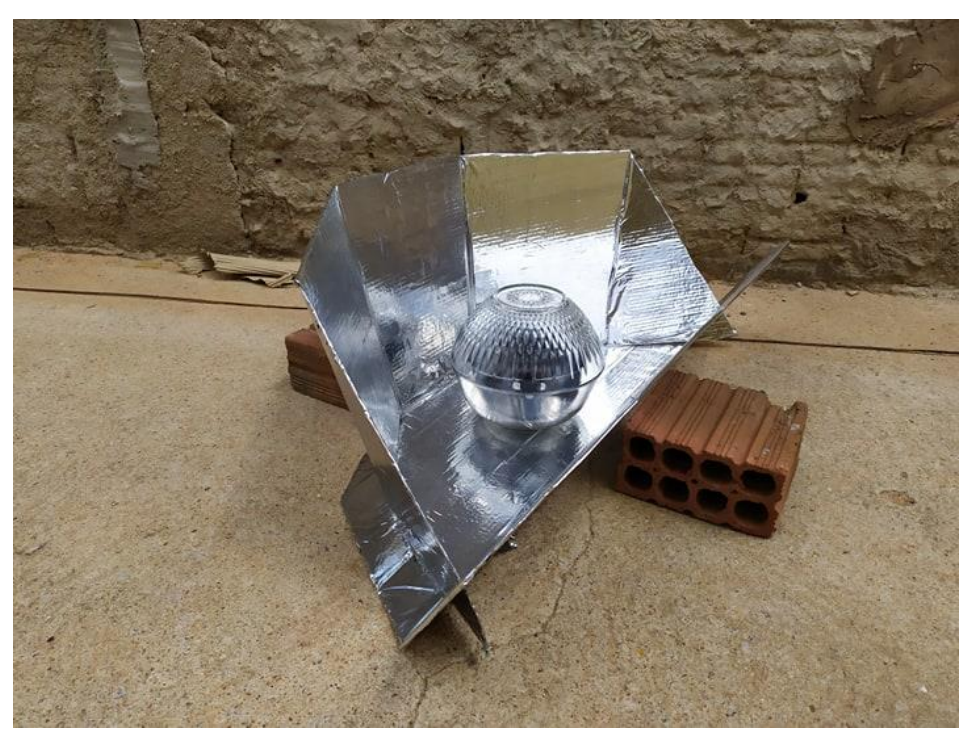

FiguRA 6. Protótipo finalizado [22].

\subsection{Procedimento Experimental}

O procedimento experimental se constituiu em um processo com o objetivo de gerar resultados, os quais são destinados para análise de desempenho do fogão solar construído. Conforme supramencionado, os resultados serão comparados analiticamente com o que foi desenvolvido por [9] em relação ao tempo de cocção, que foi o parâmetro utilizado metodologicamente e implica na necessidade de cozinhar os mesmos alimentos utilizados por [9], que foram cenoura, beterraba e chuchu.

Desse modo, tais alimentos foram cozinhados, respectivamente, nos dias 15/01/2020, 16/01/2020 e 17/01/2020, de forma que a localização do experimento foi na cidade de Mossoró/RN, mais especificamente, no bairro Planalto 13 de Maio. Além disso, com o objetivo de aperfeiçoar os resultados na cocção dos alimentos, o fogão solar foi posicionado em direção ao Sol, seguindo as recomendações da literatura, e fixado com tijolos para evitar seu deslocamento através da ação do vento, conforme já mostrado na Figura 6. 


\section{RESULTADOS}

Com a execução e finalização do procedimento experimental nos dias supracitados, foram cronometrados os tempos de cocção dos alimentos, de modo que tais resultados estão destacados na Tabela 2.

TABELA 2. Resultados da cocção [22].

\begin{tabular}{ccccc}
\hline Alimento & Dia da cocção & $\begin{array}{c}\text { Horário de } \\
\text { início }(h)\end{array}$ & $\begin{array}{c}\text { Horário de } \\
\text { término }(h)\end{array}$ & $\begin{array}{c}\text { Tempo } \\
\text { totalizado }\end{array}$ \\
\hline Cenoura & $15 / 01 / 2020$ & $10: 22$ & $13: 18$ & $\begin{array}{c}2 \text { horas e } 56 \\
\text { minutos }\end{array}$ \\
Beterraba & $16 / 01 / 2020$ & $11: 22$ & $13: 57$ & $\begin{array}{c}2 \text { horas e } 35 \\
\text { minutos } \\
1 \text { hora e } 48 \\
\text { minutos }\end{array}$ \\
\hline
\end{tabular}

A Figura 7 permite a visualização dos alimentos antes e depois do processo de cocção.

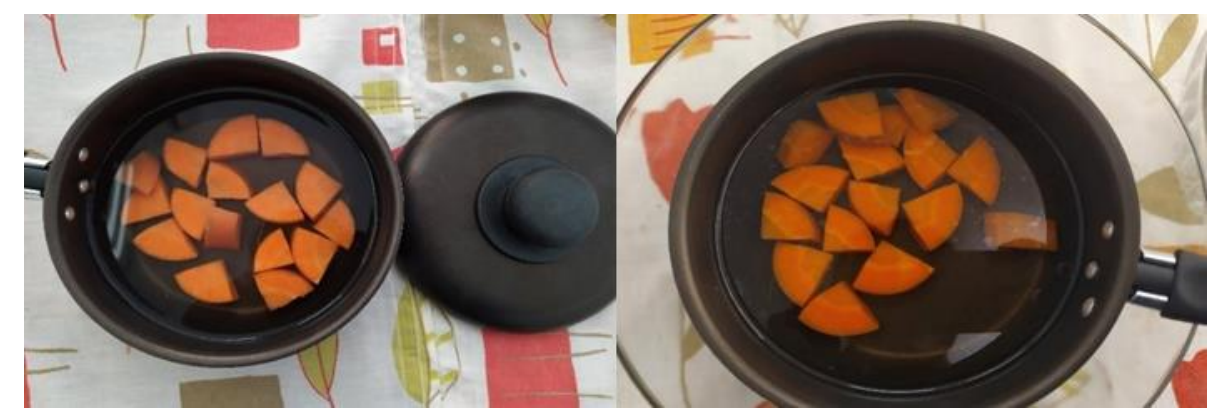

(a)

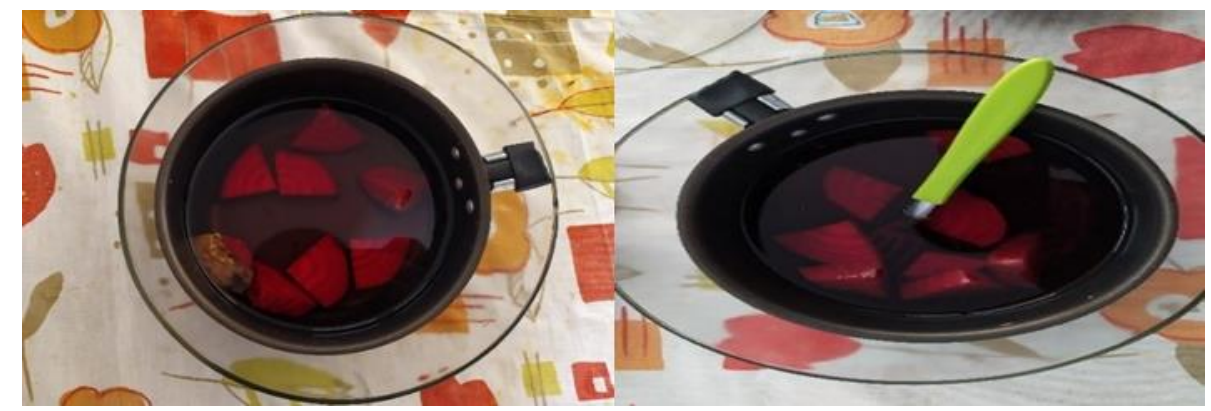

(b)

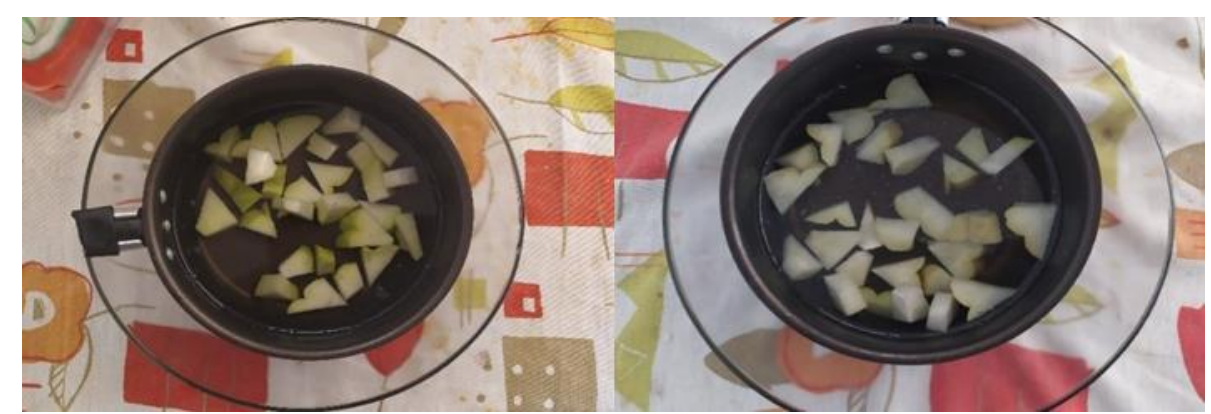

(c)

FiguRA 7. Cenoura (a), beterraba (b) e chuchu (c), antes e após a cocção destes alimentos [22].

Na Tabela 3 está representado o tempo de cocção dos alimentos em comparação aos resultados obtidos por [9]. 
TABELA 3. Comparação entre os tempos de cocção [9,22].

\begin{tabular}{ccc}
\hline \multirow{2}{*}{ Alimento } & \multicolumn{2}{c}{ Tempo de cocção } \\
\cline { 2 - 3 } & $\begin{array}{c}\text { Artigo da } \\
\text { referência [22] }\end{array}$ & {$[9]$} \\
\hline \multirow{2}{*}{ Cenoura } & 2 horas e 56 & 1 hora e 20 \\
& minutos & minutos \\
Beterraba & 2 horas e 35 & 1 hora e 20 \\
& minutos & minutos \\
Chuchu & 1 hora e 48 & 1 hora e 20 \\
& minutos & minutos \\
\hline
\end{tabular}

Analisando-se os resultados mostrados na Tabela 3, é possível identificar que o fogão desenvolvido neste artigo apresentou um menor rendimento em comparação ao fogão construído por [9], isto se deve possivelmente ao fato de que nos dias em que os experimentos foram realizados, a cidade de Mossoró/RN encontrava-se em tempo parcialmente nublado [23], o que dificultou a cocção dos alimentos devido à variação constante entre os níveis de irradiação incidentes no local. Em relação ao cozimento do chuchu, por exemplo, no dia da realização do experimento, o céu encontrava-se limpo, com pouca presença de nebulosidade e a duração de cocção apresentou-se mais próxima aos resultados obtidos por [9]. Desse modo, acredita-se que em um contexto com o tempo mais limpo e firme, que é como se apresenta o município de Mossoró/RN na maior parte do ano, certamente o fogão solar desenvolvido neste artigo apresentaria um melhor desempenho.

\section{CONCLUSÃO}

Através da literatura, foi possível identificar que a energia solar pode ser utilizada na cocção de alimentos por intermédio de diversos modelos de fogões, de modo que, no presente artigo, foi selecionado o fogão solar do tipo painel modelo cookit para ser construído com materiais de baixo custo, que foi confeccionado com êxito de forma rápida e econômica. Além disso, em relação à verificação da viabilidade deste modelo de fogão na cidade de Mossoró/RN, conclui-se que há pouca literatura que aborda os fornos solares do tipo painel, principalmente em relação ao seu desempenho, o que dificultou a realização de uma análise mais precisa e parametrizada.

Contudo, a partir da análise comparativa realizada, é possível concluir que o fogão solar construído e desenvolvido neste artigo apresentou maior tempo de cocção devido ao contexto climático que se encontrava a cidade Mossoró/RN no período de testes. O clima com grande precipitação de nuvens prejudica o funcionamento de fogões solares do tipo painel, o que se resulta em um menor desempenho de cocção e em uma análise com baixa precisão sobre o processo estudado.

Todavia, apesar do cenário apresentado, o fogão solar realizou o processo de cozimento dos alimentos: cenoura, beterraba e chuchu, mesmo que utilizando-se de um tempo maior do que o da literatura utilizada como referência. Ainda assim, a análise de desempenho não deve ser o suficiente para afirmar se fogões solares do tipo painel apresentam-se como viáveis ou não na cidade de Mossoró/RN, pois como já mencionado, a cidade possui clima semiárido e apresenta irradiação solar intensa na maior parte do ano, o que favorece um elevado potencial de energia solar a ser explorado por meio de fogões solares do tipo painel, os quais possuem construção de baixo custo e relativamente rápida. Além disso, esses fogões utilizando a energia solar para cocção de alimentos diversos, também surgem para contribuir de forma alternativa ao fogão a lenha ou fogão à gás liquefeito de petróleo (GLP), o que resulta em um desenvolvimento sustentável do município, impactando positivamente todas as esferas locais, sejam elas políticas, sociais ou econômicas.

Por fim, é necessário ressaltar que este trabalho consiste em apenas um dos trabalhos iniciais sobre fogões solares do tipo painel na região do semiárido nordestino, de modo que, para desenvolvimento de futuros trabalhos sobre o tema, recomenda-se a comparação do cozimento deste fogão com um modelo a gás convencional ou com os outros tipos de fogões solares já mencionados e a medição da irradiação incidente, da temperatura ambiente e do interior da panela em determinados intervalos de tempo, pois desse modo será realizada uma análise mais precisa e detalhada deste tipo específico de fogão solar.

\section{REFERÊNCIAS}

[1] VILlalVA, M. G. Energia Solar Fotovoltaica: Conceitos e Aplicações, 2rd ed.; Editora: Érica, Brasil, 2012; p. 16-20. 
[2] VARELLA, F. Energia. Mossoró: Slides, 2019. 69 slides, color.

[3] ESTENDER, A. C.; PITTA, T. de T. M. O Conceito de Desenvolvimento Sustentável. Terceiro Setor 2008, v. 2, 77 p.

[4] IMHOFF, J. Desenvolvimento de Conversores Estáticos para Sistemas Fotovoltaicos Autônomos. Dissertação, Universidade Federal de Santa Maria, Santa Maria, 2007.

[5] ALMEIDA, I. B. de; LIMA, M. A. A.; SOUZA, L. G. M. de. Desenvolvimento de Secador Solar Construído a partir de Material Reciclável. Holos 2016, v. 4, 422 p.

[6] OLIVEIRA, E. M.; PALHETA, G. S.; SEABRA, L. B. O Ensino de Ciências e Energias Renováveis: Proposta Metodológica do Forno e Fogão Solar. Ciência e Natura 2017, v. 39, 201 p.

[7] SILVEIRA FILHO, E. D. da. Entrevista. Mix Sustentável 2016, v. 2, 120 p.

[8] Solar Cookers International. Disponível online: <https://solarcooking.fandom.com/wiki/Introduction_to_solar_cooking> (acesso em 15/01/2020).

[9] SARMENTO, J. S. Construção e Análise de um Forno Solar como uma Atividade Prática Não Formal no Ensino da Física. Dissertação, Universidade Federal do Ceará, Fortaleza, 2015.

[10] CUCE, E.; CUCE, P. M. A Comprehensive Review on Solar Cookers. Applied Energy 2013, v. 102, 1534 $\mathrm{p}$.

[11] CORIOLANO, D. L.; SILVA, E. D. L. da; ANDRADE, V. C. V.; RESENDE, I. T. F. de; ARAÚJO, M. E. A. de; FIGUEIREDO, R. T.; ALSINA, O. L. S. Projeto, Desenvolvimento e Teste de Fogões Solares. Em Anais do Congresso Brasileiro de Energia Solar, Gramado, Brasil, 2018.

[12] VARELA, P. H. de A. Viabilidade Térmica de um Forno Solar Fabricado com Sucatas de Pneus. Dissertação, Universidade Federal do Rio Grande do Norte, Natal, 2013.

[13] Solar Cookers International. Disponível online: <https://solarcooking.fandom.com/wiki/Minimum_Solar_Box_Cooker> (acesso em 17/01/2020).

[14] Insteading. Disponível online: <https://insteading.com/blog/solar-cooker/> (acesso em 17/01/2020).

[15] SANTOS FILHO, E. A.; SILVA, V. C. da. Construção e Teste de Forno Solar. Trabalho de Conclusão, Faculdade de Aracruz, Aracruz, 2008.

[16] Ifixit. Disponível online: <https://pt.ifixit.com/Device/Parabolic_Solar_Cooker> (acesso em 17/01/2020).

[17] RAMOS FILHO, R. E. B. Análise de Desempenho de um Fogão Solar Construido a partir de Sucatas de Antenas de TV. Dissertação, Universidade Federal do Rio Grande do Norte, Natal, 2011.

[18] TOONEN, H. M. Adapting to an Innovation: Solar Cooking in the Urban Households of Ouagadougou (Burkina Faso). Physics and Chemistry of the Earth, Parts A/B/C 2009, v. 34, 1032 p.

[19] IDEMA - RN. Disponível online: <http://adcon.rn.gov.br/ACERVO/idema/DOC/DOC000000000013950.PDF Cooker> (acesso em 17/01/2020).

[20] Usina Solar UFERSA. Disponível online: <https://usinasolar.ufersa.edu.br/geracao-de-energia-eletrica/> (acesso em 17/01/2020).

[21] Solar Cookers International. Disponível online: <http://solarcooking.org/portugues/cookit-pt.htm> (acesso em 17/01/2020).

[22] FAUSTINO NETO, C. A. Construção de um Fogão Solar do Tipo Painel com Materiais de Baixo Custo. Trabalho de Conclusão, Universidade Federal Rural do Semi-Árido do Rio Grande do Norte, Mossoró, 2020.

[23] Time and Date. Disponível online: <https://www.timeanddate.com/weather/brazil/mossoro/historic> (acesso em 17/01/2020). 